\title{
Features of experimental modeling of tuberculosis in guinea pig with the participation of $N^{\prime}=(2-(5-(($ thephylline-7'-yl)methyl)-4-R-1,2,4- triazole-3-ylthio)acethyl)isonicotinohydrazide
}

\author{
A.S. Gotsulya1, V.V. Zazhzharskiy², P.O. Davidenko², N.M. Zazhzharskaya², O.M. Kulishenko²,

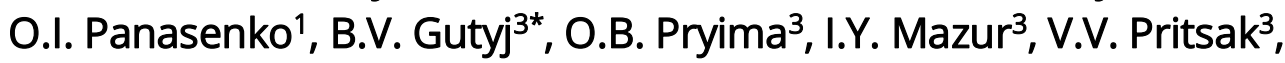 \\ U.R. Drachuk ${ }^{3}$, A.G. Sobolta ${ }^{3}$, M.B. Riy ${ }^{3}$ \\ 'Zaporizhzhia State Medical University, Zaporizhzhia, Ukraine \\ ${ }^{2}$ Dnipro State Agrarian and Economic University, Dnipro, Ukraine \\ ${ }^{3}$ Stepan Gzhytskyi National University of Veterinary Medicine and Biotechnologies, Lviv, Ukraine \\ *Corresponding author E-mail: bvh@ukr.net \\ Received: 20.08.2020. Accepted 26.09.2020
}

\begin{abstract}
In this study, no toxic effects were detected after single subcutaneous injection of $40 \mathrm{mg} / \mathrm{kg}$ tadpoles. The results of macro- and microscopic examination of the internal organs 14 days after single subcutaneous administration of $N^{\prime}-(2-(5-($ thephylline-7'yl)methyl)-4-ethyl-1,2,4-triazole-3-ylthio)acethyl)isonicotino-hydrazide (GKP-305) at a dose of 20, $40 \mathrm{mg} / \mathrm{kg}$ showed the absence of any anatomical and morphological abnormalities in the tissue structures of the tentacles. The calculated value of the drug indicates a high degree of safety GKP-305 and its prospects for veterinary practice as an effective and safe tuberculocidal drug. Key words: Tuberculosis, 1,2,4-triazole, modeling, guinea pig.
\end{abstract}

\section{Introduction}

The advent of 1,2,4-triazole drugs has revolutionized the treatment of people with invasive and fungal infections (Neofytos, 2010; Haegler et al., 2017; Gotsulia et al., 2018; Zazharskyi et al., 2019). However, keep in mind that drugs with a fragment of triazole can cause various side effects and can sometimes interact with other drugs (Samelyuk \& Kaplaushenko, 2015; Fard et al., 2016; Bihdan et al., 2019; Palchykov et al., 2020).

Haegler et al. (2017) noted that in HepG2 cells (human hepatocarcinoma), posaconazole and ketoconazole were cytotoxic starting at 20 and $50 \mu \mathrm{M}$, and decreased cellular ATP content starting at 5 and $10 \mu \mathrm{M}$. Fard et al. (2016) found a negative effect of risatriptan on hepatocytes. Hepatocyte lysosomes and mitochondria have been shown to play an important role in risatriptan-induced cell injury (Chachibaia \& Hoskeri, 2016).

\section{Materials and methods}

Acute toxicity of the preparation GKP-305 was determined on 12 nonlinear tussles of both sexes with an average mass of 250 g. There were formed 4 groups of animals of 3 animals in each group (Stephanov, 2001).

Group 1: subcutaneous administration of the drug at a dose of $20 \mathrm{mg} / \mathrm{kg}$ animal weight - a double dose of tuberculosis in the treatment of this drug.

Group 2: at a dose of $40 \mathrm{mg} / \mathrm{kg}$ animal weight.

Group 3: use of the preparation GKP-305 at a dose of $80 \mathrm{mg} / \mathrm{kg}$ animal weight.

Control group: clinically healthy animals (CDD) - subcutaneous administration of isotonic sodium chloride solution (6 ml/kg). The evaluation of the effect of the study drug was performed on the following indicators:

a) mortality (the timing of the death of animals in each group, daily);

b) evaluation of manifestations of toxicity (daily), including evaluation of the appearance of the area of introduction (presence of irritation, hyperemia, edema);

c) dynamics of change of body weight (in the initial state on 4, 7 and 14 days after introduction);

d) macroscopy of internal organs, mass coefficients of internal organs in tadpoles (14 days).

Chronic toxicity of the preparation GKP-305 was determined on 12 guinea pigs with an average weight of $250 \mathrm{~g}$. There were formed 4 groups of animals of 3 animals in each group, which were re-injected the drug in doses, as in the experiment, studying acute toxicity for 3 months. The toxicity of GKP-305 was studied according to the indicators of irritant effect, emotional and behavioral reactions of laboratory animals and determined the coefficients of mass of internal organs for long-term administration of the drug. 
We also calculated the mass ratio (MK) as the percentage of body mass to body weight, an integral indicator used to evaluate the condition of internal organs. The calculation of the mass coefficients was determined by the formula:

MK = organ weight $(\mathrm{g}) /$ body weight $(\mathrm{g}) \times 100 \%$

Animals were kept under standard conditions. Experiments conducted on live vertebrates conformed to the principles of the European Convention on the Protection of Vertebrate Animals, used for research and other scientific purposes (Strasbourg, 1986). Total serum protein was investigated by biuret method, albumin concentration by B. Doumas et al., Residual nitrogen content by color reaction with Nessler reagent, nitrogen concentration of free amino acids by GA method. Uzbekova in the modification of ZS Chulkovy, urea content - according to Marsh, creatinine concentration - according to the Popper method, activity of ALAT and AsAT - according to Reitman and Frenkel. The data in the tables are presented as X $\pm 1.96 \mathrm{SD}$.

\section{Results and discussion}

After administration of the preparations, the animals were monitored for 14 days and their general condition, mortality, and body weight dynamics were evaluated. Indicators of acute toxicity of the GKP-305 with subcutaneous injection of tadpoles in different doses are presented in Table 1.

Table 1. Indicators of acute toxicity of the GKP-305, $n=10$

\begin{tabular}{lcccc}
\hline Group of animals & $\begin{array}{c}\text { Dose } \\
\mathrm{mg} / \mathrm{kg}\end{array}$ & $\begin{array}{c}\text { The number of dead } \\
\text { animals }\end{array}$ & $\begin{array}{c}\text { The number of surviving } \\
\text { animals }\end{array}$ & Mortality rate, \% \\
\hline I & 20.0 & 0 & 3 & 0 \\
II & 40.0 & 0 & 3 & 0 \\
III & 80.0 & 1 & 2 & 33.3 \\
Control & - & 0 & 3 & 0 \\
\hline
\end{tabular}

As a result, the study found that after single subcutaneous administration to animals of the experimental groups, changes in behavior and activity did not occur. Also, no signs of intoxication and animal death were observed except for group III - 1 were killed. Thus, $L_{50}$ for GKP-305 in the acute toxicity phase determined $40.0 \mathrm{mg} / \mathrm{kg}$ animal weight. According to the acute toxicity study, the dynamics of body weight of animals of all groups were studied to evaluate the toxic effects of potential drugs on mammals (table 2).

Table 2. Dynamics of body weight of animals

\begin{tabular}{lccc}
\hline \multirow{2}{*}{ Group of animals } & \multicolumn{3}{c}{ Days of observation / Body weight, g } \\
\cline { 2 - 4 } I & 1 & 7 & $348.5 \pm 15.6^{* *}$ \\
II & $292.6 \pm 8.7$ & $302.8 \pm 13.6^{*}$ & $347.4 \pm 11.5$ \\
III & $287.3 \pm 11.3$ & $303.5 \pm 10.4$ & $424.8 \pm 13.6^{* * *}$ \\
Control & $291.8 \pm 12.5$ & $311.4 \pm 12.2^{* * *}$ & $365.3 \pm 12.7^{* * *}$ \\
\hline
\end{tabular}

Note: ${ }^{*}(\mathrm{P}<0.05) i^{* *}(\mathrm{P}<0.01) i^{* * *}(\mathrm{P}<0.001)$.

We determined that the animals in groups I and II on the 7th day of observation did not differ from the control, and on the 14th day slightly lagged in body weight by 18.0 and $17.0 \mathrm{~g}$, respectively. In animals of group III, on the contrary, body weight on the 7 th day of observation was higher than the control by 6.0; and on day 14, $59.0 \mathrm{~g}(\mathrm{P}<0.05)$, respectively.

On the 14th day of observation, all animals had a neat wool blanket, unchanged mucous membranes of natural openings. Subcutaneous lymph nodes are normal in size and to the touch. The study of the morpho-biochemical parameters of the blood of the tunicates with long-term administration of the GKP-305 are shown in Tables 3 and 4.

Most plasma proteins are synthesized by the liver. Note the increase in total protein in the III experimental group after drug use in comparison with I, II and intact animal group by $24.6(P<0.05) ; 12.9$ and $15.9 \%$ due to globulins by $41.2(P<0.05) ; 29.6$ $(P<0.05)$; and $30.1 \%(P<0.05)$, respectively. There was also a sharp decrease in protein ratio in the experimental group III by $40.0 \%(P<0.05)$ than in animals I and 30.8\% $(P<0.05)$ in group II and control.

AST in the first experimental group for long-term administration of GKP-305 decreased by $27.7 \%$ and was 2.0 times ( $<<0.05$ ) below control, whereas this indicator in the animals of group III exceeded the intact tussles by 3.0 times ( $<<0.05)$. Aspartate aminotransferase catalyzes the formation of glutamic acid from 2-oxoglutarate by the transfer of an amino group. AST in maximum concentration is found in the liver, heart and skeletal muscles. Increasing the serum AST concentration in group III animals is, in our opinion, associated with dysfunctional changes in the liver.

After the application of the test preparation in the troughs of group III there was an increase of alkaline phosphatase by $34.8 \%$, which is by $19.7(P<0.05) ; 12.4$ and $14.6 \%$ higher than in I, II and controls, respectively. Alkaline phosphatase catalyzes the hydrolysis of organic phosphate monoesters in an alkaline medium. The enzyme is present in almost all tissues of the body, especially in cell membranes, and is found in especially high concentrations in the placenta, intestinal epithelium, renal tubules, osteoblasts and liver. Increase in alkaline phosphatase content in group III may be associated with hepatobiliary disorders drug-induced hepatotoxicity. 


\begin{tabular}{|c|c|c|c|c|c|c|c|c|}
\hline \multirow{3}{*}{ Indicators } & \multicolumn{8}{|c|}{ Group of animals } \\
\hline & \multicolumn{2}{|c|}{ I } & \multicolumn{2}{|c|}{ II } & \multicolumn{2}{|c|}{ III } & \multicolumn{2}{|c|}{ Control } \\
\hline & Before & After & Before & After & Before & After & Before & After \\
\hline $\begin{array}{l}\text { Total } \\
\text { protein, g/L }\end{array}$ & $54.2 \pm 3.4$ & $51.3 \pm 3.8$ & $53.9 \pm 4.2$ & $59.2 \pm 4.3$ & $55.2 \pm 3.6$ & $68.1 \pm 4.3^{*}$ & $55.0 \pm 3.4$ & $57.2 \pm 2.9^{*}$ \\
\hline Albumin, g/L & $33.1 \pm 2.6$ & $31.5 \pm 3.6$ & $33.0 \pm 2.9$ & $33.5 \pm 3.4$ & $32.9 \pm 3.2$ & $32.0 \pm 4.1$ & $33.2 \pm 3.5$ & $32.0 \pm 3.9$ \\
\hline $\begin{array}{l}\text { Globulins, } \\
\text { g/L }\end{array}$ & $21.1 \pm 1.7$ & $21.3 \pm 2.1$ & $20.9 \pm 2.5$ & $25.5 \pm 2.6$ & $22.3 \pm 2.8$ & $36.2 \pm 3.6^{* *}$ & $21.8 \pm 2.5$ & $25.3 \pm 2.8^{*}$ \\
\hline $\begin{array}{l}\text { Protein } \\
\text { ratio, U }\end{array}$ & $1.6 \pm 0.21$ & $1.5 \pm 0.32$ & $1.6 \pm 0.12$ & $1.3 \pm 0.32$ & $1.5 \pm 0.23$ & $0.9 \pm 0.16$ & $1.5 \pm 0.12$ & $1.3 \pm 0.34$ \\
\hline $\begin{array}{l}\text { Urea, } \\
\text { mmol/L }\end{array}$ & $4.0 \pm 0.43$ & $4.25 \pm 0.78$ & $3.5 \pm 0.36$ & $4.7 \pm 0.67$ & $4.1 \pm 0.36$ & $3.9 \pm 0.64$ & $3.7 \pm 0.55$ & $4.8 \pm 0.76$ \\
\hline $\begin{array}{l}\text { Blood urea } \\
\text { nitrogen, } \\
\text { mg\% }\end{array}$ & $7.1 \pm 0.78$ & $8.1 \pm 1.1$ & $7.0 \pm 0.81$ & $8.95 \pm 1.3$ & $6.8 \pm 0.78$ & $7.5 \pm 1.1$ & $6.5 \pm 0.89$ & $9.2 \pm 0.77$ \\
\hline $\begin{array}{l}\text { Creatinine, } \\
\mu \mathrm{mol} / \mathrm{L}\end{array}$ & $66.5 \pm 6.4$ & $92.3 \pm 7.4^{*}$ & $62.3 \pm 5.6$ & $\underset{*}{129.2 \pm 10.3^{* *}}$ & $60.1 \pm 5.9$ & $\underset{*}{143.8 \pm 12.6^{* *}}$ & $56.1 \pm 6.2$ & $118.1 \pm 9.9^{\star \star \star}$ \\
\hline AST, U/L & $89.2 \pm 8.9$ & $64.5 \pm 6.4^{*}$ & $82.4 \pm 9.6$ & $12.3 \pm 11.2^{*}$ & $79.2 \pm 7.5$ & $\underset{*}{388.2 \pm 21.9^{* *}}$ & $69.1 \pm 5.7$ & $\underset{*}{130,3 \pm 11.5^{* *}}$ \\
\hline $\mathrm{ALT}, \mathrm{U} / \mathrm{L}$ & $80.3 \pm 6.8$ & $49.5 \pm 5.9^{\star *}$ & $78.9 \pm 7.6$ & $80.5 \pm 8.3^{* *}$ & $73.5 \pm 7.4$ & $72.2 \pm 6.8^{*}$ & $63.5 \pm 6.4$ & $67.1 \pm 7.2$ \\
\hline AST/ALT, U & $1.1 \pm 0.21$ & $1.2 \pm 0.34$ & $1.0 \pm 0.19$ & $1.5 \pm 0.32$ & $1.1 \pm 0.12$ & $5.4 \pm 0.67^{\star * \star}$ & $1.1 \pm 0.12$ & $1.9 \pm 0.14^{\star \star \star}$ \\
\hline $\begin{array}{l}\text { Alkaline } \\
\text { phosphatas } \\
\text { e, U/L }\end{array}$ & $\begin{array}{c}200.3 \pm 13 \\
6\end{array}$ & $\begin{array}{c}244.3 \pm 16 \\
1\end{array}$ & $\begin{array}{c}234.4 \pm 11 \\
8\end{array}$ & $266.4 \pm 13.7$ & $\begin{array}{c}198.3 \pm 12 \\
8\end{array}$ & $\underset{*}{304.2 \pm 19.4^{* *}}$ & $\begin{array}{c}193.1 \pm 12 \\
7\end{array}$ & $259.9 \pm 15.7^{\star *}$ \\
\hline $\begin{array}{l}\text { Total } \\
\text { bilirubin, } \\
\text { mol/L }\end{array}$ & $3.6 \pm 0.54$ & $3.6 \pm 0.45$ & $3.5 \pm 0.53$ & $14.7 \pm 1.9^{* * *}$ & $3.4 \pm 0.64$ & $12.8 \pm 1.3^{\star * \star}$ & $\underset{*}{3.4 \pm 0.54^{* *}}$ & $12.1 \pm 1.1$ \\
\hline $\begin{array}{l}\text { Glucose, } \\
\mathrm{mmol} / \mathrm{L}\end{array}$ & $5.8 \pm 0.45$ & $7.6 \pm 0.63$ & $6.5 \pm 0.72$ & $12.9 \pm 1.3^{\star * \star}$ & $7.0 \pm 0.97$ & $10.1 \pm 1.3$ & $7.2 \pm 0.88$ & $13.6 \pm 1.6^{* *}$ \\
\hline $\mathrm{Ca}, \mathrm{mmol} / \mathrm{L}$ & $3.7 \pm 0.57$ & $2.25 \pm 0.31$ & $3.0 \pm 0.42$ & $2.55 \pm 0.32$ & $3.3 \pm 0.48$ & $2.3 \pm 0.32$ & $3.1 \pm 0.43$ & $2.7 \pm 0.31$ \\
\hline $\mathrm{P}, \mathrm{mmol} / \mathrm{L}$ & $4.2 \pm 0.44^{* *}$ & $1.75 \pm 0.67$ & $3.8 \pm 0.59$ & $2.7 \pm 0.33$ & $3.9 \pm 0.21$ & $2.9 \pm 0.42$ & $3.7 \pm 0.37$ & $2.4 \pm 0.19$ \\
\hline $\mathrm{Ca} / \mathrm{P}, \mathrm{U}$ & $0.9 \pm 0.13$ & $1.3 \pm 0.21$ & $0.8 \pm 0.12$ & $0.9 \pm 0.14$ & $0.8 \pm 0.16$ & $0.8 \pm 0.14$ & $0.8 \pm 0,22$ & $1.1 \pm 0.11$ \\
\hline $\begin{array}{l}\text { Cholesterol, } \\
\mathrm{mmol} / \mathrm{L}\end{array}$ & $1.6 \pm 0.21$ & $1.45 \pm 0.32$ & $1.5 \pm 0.34$ & $1.15 \pm 0.43$ & $1.4 \pm 0.32$ & $1.4 \pm 0.25$ & $1.5 \pm 0.18$ & $1.0 \pm 0.12$ \\
\hline
\end{tabular}

Table 4. Morphological indices of guinea pig blood with prolonged administration of GKP-305 $(n=10)$

\begin{tabular}{|c|c|c|c|c|c|c|c|c|}
\hline \multirow{3}{*}{ Indicators } & \multicolumn{8}{|c|}{ Group of animals } \\
\hline & \multicolumn{2}{|c|}{1} & \multicolumn{2}{|c|}{ II } & \multicolumn{2}{|c|}{ III } & \multicolumn{2}{|c|}{ Control } \\
\hline & Before & After & Before & After & Before & After & Before & After \\
\hline Hemoglobin, g/L & $108.5 \pm 9.5$ & $130.5 \pm 11.4$ & $111.3 \pm 8.9$ & $113.3 \pm 13.1$ & $118.5 \pm 10.9$ & $112.0 \pm 9.8$ & $119.8 \pm 12.6$ & $92.4 \pm 8.9$ \\
\hline Hematocrit, \% & $37.5 \pm 5.6$ & $41.2 \pm 4.1$ & $35.3 \pm 3.6$ & $40.3 \pm 4.7$ & $36.5 \pm 3.7$ & $39.3 \pm 5.2$ & $35.9 \pm 4.9$ & $34.3 \pm 3.9$ \\
\hline Erythrocytes, $10^{12} / \mathrm{L}$ & $4.1 \pm 0.2$ & $5.1 \pm 0.6$ & $4.7 \pm 0.7$ & $4.8 \pm 0.5$ & $4.1 \pm 0.4$ & $4.6 \pm 0.3$ & $3.9 \pm 0.2$ & $4.1 \pm 0.3$ \\
\hline ESR, mm/hour & $1.0 \pm 0.1$ & $1.1 \pm 0.1$ & $0.9 \pm 0.1$ & $1.0 \pm 0.1$ & $1.0 \pm 0.1$ & $1.0 \pm 0.1$ & $1.0 \pm 0.1$ & $1.0 \pm 0.1$ \\
\hline Platelets, $10^{9} / \mathrm{L}$ & $285.3 \pm 14.4$ & $347.2 \pm 23.11^{*}$ & $273.5 \pm 15.8$ & $274.5 \pm 16.8$ & $223.2 \pm 13.9$ & $263.1 \pm 14.7$ & $266.5 \pm 14.9$ & $276.2 \pm 15.2^{*}$ \\
\hline Leukocytes, $10^{9} / \mathrm{L}$ & $6.5 \pm 0.2^{* * *}$ & $3.3 \pm 0.16$ & $4.5 \pm 0.34^{* * *}$ & $1.8 \pm 0.22$ & $4.3 \pm 0.35^{* * *}$ & $1.9 \pm 0.17$ & $4.1 \pm 0.5^{* * *}$ & $2.0 \pm 0.14$ \\
\hline \multicolumn{9}{|c|}{ Leucocyte formula, \% } \\
\hline Basophils & 0 & 0 & 0 & 0 & 0 & 0 & 0 & 0 \\
\hline Eosinophils & $1.0 \pm 0.1$ & $1.0 \pm 0.1$ & $1.0 \pm 0.1$ & $1.0 \pm 0.1$ & $1.0 \pm 0.1$ & $1.0 \pm 0.1$ & $1.0 \pm 0.1$ & $2.0 \pm 0.1$ \\
\hline \multicolumn{9}{|l|}{ Neutrophils } \\
\hline Myelocytes & 0 & 0 & 0 & 0 & 0 & 0 & 0 & 0 \\
\hline Young cell & 0 & 0 & 0 & 0 & 0 & 0 & 0 & 0 \\
\hline Band cell & $2.0 \pm 0.12$ & $1.5 \pm 0.1$ & $2.0 \pm 0.21$ & $1.5 \pm 0.23$ & $1.0 \pm 0.1$ & $3.0 \pm 0.25^{* * *}$ & $2.0 \pm 0.11$ & $2.0 \pm 0.14$ \\
\hline Granulocytes & $38.5 \pm 5.6$ & $28.3 \pm 2.5$ & $35.5 \pm 4.7$ & $25.4 \pm 5.7$ & $41.0 \pm 7.4$ & $30.5 \pm 4.6$ & $35.1 \pm 3.6$ & $41.2 \pm 5.7$ \\
\hline Lymphocytes & $53.5 \pm 6.9$ & $66.5 \pm 7.8$ & $56.0 \pm 5.8$ & $71.5 \pm 10.3$ & $50.8 \pm 8.9$ & $65.0 \pm 9.7$ & $54.0 \pm 8.8$ & $46.2 \pm 7.8$ \\
\hline Monocytes & $5.2 \pm 0.45^{* * *}$ & $2.7 \pm 0.42$ & $5.5 \pm 0.37^{* * *}$ & $0.6 \pm 0.32$ & $6.2 \pm 0.53^{* \star *}$ & $0.5 \pm 0.12$ & $7.9 \pm 0.42$ & $8.6 \pm 1.2^{* \star \star}$ \\
\hline
\end{tabular}

Note: ${ }^{*}(\mathrm{P}<0.05){ }^{* *}(\mathrm{P}<0.01) i^{* * *}(\mathrm{P}<0.001)$.

Urea is synthesized in the liver as a by-product of the amino acid deamination reaction. Its elimination in the urine is the main route of excretion of nitrogen. The reduced concentration of urea in the plasma of the troughs of group III is a consequence of the decrease in protein catabolism and weak dehydration. This is lower than group I, group II and intact animals by $8.2 ; 17.0$ 
and $18.8 \%(\mathrm{P}<0.05)$, respectively. Blood plasma creatinine determines the glomerular filtration rate, an integral indicator of renal excretory function. We noted an increase in creatinine in animals in the experimental group III compared to tadpoles I, II and intact animals by $35.8(P<0.05) ; 10.2$ and $17.9 \%(P<0.05)$, respectively. An increase in this indicator indicates the presence of an inflammatory reaction in the body of group III tentacles. Blood biochemical parameters in animals of the first and second experimental groups are within the physiological norm. Analyzing the morphological indices of murch blood with prolonged administration of GKP-305, we note an increase in the number of rod-core neutrophils in group III animals compared to I, II and intact murchak by 2.0 (P<0.05); 2.0 $(P<0.05)$ and 1.5-fold $(P<0.05)$ against a decrease of $5.4(P<0.05)$ monocytes; 1.2 and $17.2(P<0.05)$ times, respectively. The mass coefficients of the internal organs of the tentacles for long-term administration of the GKP-305 is presented in Table 5.

Table 5. Mass coefficients of the internal organs of the tentacles for prolonged administration of the GKP-305, $g$, M $\pm m$

\begin{tabular}{|c|c|c|c|c|c|c|c|c|}
\hline \multirow{3}{*}{ Indicators } & \multicolumn{8}{|c|}{ Group of animals } \\
\hline & \multicolumn{2}{|c|}{1} & \multicolumn{2}{|c|}{ II } & \multicolumn{2}{|c|}{ III } & \multicolumn{2}{|c|}{ Control } \\
\hline & $\begin{array}{c}\text { Body } \\
\text { weight }\end{array}$ & Mass ratio & $\mathrm{IOM}$ & Mass ratio & IOM & Mass ratio & IOM & Mass ratio \\
\hline Body weight & $348.5 \pm 15.6$ & - & $347.4 \pm 11.5$ & - & $347.4 \pm 11.5$ & - & $347.4 \pm 11.5$ & - \\
\hline Heart & $1.45 \pm 0.12$ & $0.42 \pm 0.02$ & $1.5 \pm 0.22$ & $0.43 \pm 0.045$ & $1.7 \pm 0.15$ & $0.41 \pm 0.02$ & $1.5 \pm 0.32$ & $0.41 \pm 0.07$ \\
\hline Lungs & $4.1 \pm 0.31$ & $1.15 \pm 0.03$ & $4.1 \pm 0.37$ & $1.18 \pm 0.025$ & $4.6 \pm 0.32$ & $1.08 \pm 0.05$ & $4.1 \pm 0.43$ & $1.12 \pm 0.07$ \\
\hline Liver & $18.2 \pm 2.11$ & $5.22 \pm 0.38$ & $18.4 \pm 3.12$ & $5.32 \pm 0.72$ & $22.2 \pm 3.56$ & $5.22 \pm 0.67$ & $17.8 \pm 2.87$ & $4.87 \pm 0.62$ \\
\hline Spleen & $0.7 \pm 0.10$ & $0.20 \pm 0.015$ & $0.6 \pm 0.17$ & $0.17 \pm 0.04$ & $1.2 \pm 0.12^{*^{*}}$ & $0.28 \pm 0.02 *$ & $0.6 \pm 0.22$ & $0.16 \pm 0.05$ \\
\hline The kidneys & $3.1 \pm 0.17$ & $0.89 \pm 0.02$ & $3.3 \pm 0.55$ & $0.94 \pm 0.13$ & $3.5 \pm 0.44$ & $0.82 \pm 0.07$ & $2.9 \pm 0.55$ & $0.79 \pm 0.12$ \\
\hline
\end{tabular}

We determined an increase in all indicators of internal organs in animals of the third experimental group in comparison with troughs I, II group and control, and the mass ratio of the spleen was higher by $28.6(P<0.05) ; 39.3(P<0.05)$ and $42.9 \%(P<0.05)$, respectively. The analysis of this indicator in toxicological studies makes it possible to identify the target organ of the toxicant, to identify signs of endocrine-related effects. The unique properties of 1,2,4-triazole make this heterocycle very attractive for research (Bihdan et al., 2019; Hunchak et al., 2020). Studies have shown the high reactivity and low toxicity of 1,2,4-triazole derivatives and the prospect of their use as potential biologically active compounds. Interesting results have also been found regarding the use of some 1,2,4-triazoles derivatives as effective plant growth regulators (Zazharskyi et al., 2019; Palchykov et al., 2020).

We have determined the safety of the use of the GKP-305 on tadpoles up to 4 times the introduction. The biochemical parameters and mass coefficients of the internal organs in animals were within the physiological control of the intact group.

The preparation GKP-305 can be used as a tuberculocide with a level of safety up to 4 times the dose.

\section{Conflicts of interest}

The authors declare that there is no conflict of interest. The authors alone are responsible for the content of the paper.

\section{References}

Bihdan, O., Parchenko, V., Zazharskyi, V., Fotina, T., \& Davydenko, P. (2019). Studying of physico-chemical properties of 5-(2-,3-fluorophenyl)-4-((aryl-, geteryl)yliden)amino-1,2,4-triazole-3-thiols and any of their retrievalproducts, Res. J. Pharm. Biol. Chem. Sci., 10(1), 464-474.

Chachibaia, T., \& Hoskeri, J. H. (2016). Predictive Toxicity of Conventional Triazole Pesticides by Simulating Inhibitory Effect on Human Aromatase CYP19 Enzyme. International Journal of Knowledge Discovery in Bioinformatics, 6(2), 44-56. doi:10.4018/ijkdb.2016070104

Fard, J., Hamzeiy, H., Sattari, M., Eftekhari, A., Ahmadian, E., \& Eghbal, M. (2016). Triazole rizatriptan Induces Liver Toxicity through Lysosomal/Mitochondrial Dysfunction. Drug Research, 66(09), 470-478. doi: 10.1055/s-0042-110178

Gotsulia, A. S., Zazharskyi, V. V., \& Davydenko, P. O. (2018). Synthesis and antituberculosis activity of N-(2-(5-((theophylline-7'-yl)methyl)-4-R-4H-1,2,4-triazole3-ylthio)acetyl)isonicotino-hydrazides. Zaporozhye medical journal, 20(4), 578-583. doi: 10.14739/2310-1210.2018.4.135677

Haegler, P., Joerin, L., Krähenbühl, S., \& Bouitbir, J. (2017). Hepatocellular Toxicity of Imidazole and Triazole Antimycotic Agents. Toxicological Sciences, 157(1), 183-195. doi:10.1093/toxsci/kfX029

Hunchak, V. M., Martynyshyn, V. P., Gutyj, B. V., Hunchak, A. V., Stefanyshyn, O. M., \& Parchenko, V. V. (2020). Impact of 1,2,4-thio-triazole derivative-based liniment on morphological and immunological blood parameters of dogs suffering from dermatomycoses. Regulatory Mechanisms in Biosystems, 11(2), 294-298. doi: 10.15421/022044

Neofytos, D. (2010). Clinical safety and tolerability issues in use of triazole derivatives in management of fungal infections. Drug, Healthcare and Patient Safety, 2, 27-38. doi: 10.2147/dhps.s6321

Palchykov, V. A., Zazharskyi, V. V., Brygadyrenko, V. V., Davydenko, P. O., Kulishenko, O M., \& Borovik, I. V. (2020). Chemical composition and antibacterial effect of ethanolic extract of Buxus sempervirens on cryogenic strains of microorganisms in vitro. Chemical Data Collections, 25, 100323.

Samelyuk, Y. G., \& Kaplaushenko, A. G. (2015). Acute toxicity of 5-(2-, 3-, 4-methoxyphenyl, (3,4,5-trimethoxyphenyl)-1,2,4-triazole-3-thiones and its thioderivatives. Current Issues in Pharmacy and Medicine: Science and Practice, 3(19), 57-60. doi: 10.14739/2409-2932.2015.3.52660

Stephanov, O. V. (2001). Doklinichni doslidzhennia likarskikh zasobiv [Preclinical studies of medicines]. Kyiv: Avicenna (in Ukrainian).

Zazharskyi, V., Davydenko, P., Kulishenko, O., Borovik, I., \& Brygadyrenko, V. (2019). Antimicrobial activity of 50 plant extracts. Biosystems Diversity, 27(2), 163-169. doi: 10.15421/011922

\section{Citation:}

Gotsulya, A.S., Zazhzharskiy, V.V., Davidenko, P.O., Zazhzharskaya, N.M., Kulishenko, O.M., Panasenko, O.I., Gutyj, B.V., Pryima, O.B., Mazur, I.Y., Pritsak, V.V., Drachuk, U.R., Sobolta, A.G., Riy, M.B. (2020). Features of experimental modeling of tuberculosis in guinea pig with the participation of N-(2-(5((thephylline-7'-yl)methyl)-4-R-1,2,4-triazole-3-ylthio)acethyl)isonicotinohydrazide. Ukrainian Journal of Ecology, 10(4), 191 -194. 